\title{
Accuracy of NEXUS II head injury decision rule in children: a prospective PREDICT cohort study
}

Franz E Babl, ${ }^{1,2,3}$ Ed Oakley, 1,2,3 Stuart R Dalziel, ${ }^{4,5}$ Meredith L Borland, ${ }^{6,7}$ Natalie Phillips, ${ }^{8}$ Amit Kochar, ${ }_{1}^{9}$ Sarah Dalton, ${ }^{10}$ John Alexander Cheek, ${ }_{1}^{1,2,11}$ Yuri Gilhotra, ${ }^{8}$ Jeremy Furyk, ${ }^{12}$ Jocelyn Neutze, ${ }^{13}$ Susan Donath, ${ }^{2,3}$ Stephen Hearps, ${ }^{2}$ Louise M Crowe, ${ }^{2}$ Marta Arpone, ${ }^{2,3}$ Silvia Bressan, ${ }^{2,14}$ Mark D Lyttle, ${ }^{2,15,16}$ For the Paediatric Research in Emergency Department International Collaborative (PREDICT)

\begin{abstract}
- Additional material is published online only. To view, please visit the journal online (http://dx.doi.org/10.1136/ emermed-2017-207435).

For numbered affiliations see end of article.
\end{abstract}

\section{Correspondence to} Dr Franz E Babl, Emergency Department, Royal Children's Hospital, Parkville VIC 3052, Australia; franz.babl@rch.org.au

Received 29 December 2017 Revised 26 June 2018 Accepted 24 July 2018 Published Online First 20 August 2018

\section{SLinked}

- http://dx.doi.org/10.1136/ emermed-2018-208151

Check for updates

(C) Author(s) (or their employer(s)) 2019. No commercial re-use. See rights and permissions. Published by BMJ.

To cite: Babl FE, Oakley E, Dalziel SR, et al. Emerg Med J 2019:36:4-11.

\begin{abstract}
Objective The National Emergency X-Radiography

Utilisation Study II (NEXUS II) clinical decision rule (CDR) can be used to optimise the use of CT in children with head trauma. We set out to externally validate this CDR in a large cohort.
\end{abstract}

Methods We performed a prospective observational study of patients aged $<18$ years presenting with head trauma of any severity to 10 Australian/New Zealand EDs. In a planned secondary analysis, we assessed the accuracy of the NEXUS II CDR (with $95 \% \mathrm{Cl}$ ) to detect clinically important intracranial injury (ICI). We also assessed clinician accuracy without the rule.

Results Of 20137 total patients, we excluded 28 with suspected penetrating injury. Median age was 4.2 years. CTs were obtained in ED for 1962 (9.8\%), of whom 377 (19.2\%) had ICI as defined by NEXUS II. 74 (19.6\% of $\mathrm{ICI}$ patients underwent neurosurgery.

Sensitivity for $\mathrm{ICl}$ based on the NEXUS II CDR was $379 / 383(99.0$ (95\% CI 97.3\% to $99.7 \%))$ and specificity was $9320 / 19726(47.2 \%$ (95\% Cl $46.5 \%$ to $47.9 \%)$ ) for the total cohort. Sensitivity in the CT-only cohort was similar. Of the 18022 children without CT in ED, 49.4\% had at least one NEXUS II risk criterion. Sensitivity for $\mathrm{ICI}$ by the clinicians without the rule was $377 / 377$ (100.0\% (95\% Cl 99.0\% to $100.0 \%)$ ) and specificity was 18 147/19 732 (92.0\% (95\% Cl 91.6\% to $92.3 \%)$ ).

Conclusions NEXUS II had high sensitivity, similar to the derivation study. However, approximately half of unimaged patients were positive for NEXUS II risk criteria; this may result in an increased CT rate in a setting with high clinician accuracy.

\section{INTRODUCTION}

\section{Background}

Over the last 20 years, a number of head injury clinical decision rules (CDRs) have been developed. They are generally designed to determine which patients should or should not undergo CT of the head by stratifying patients into those at increased or decreased risk of intracranial injury (ICI). In children with head injuries, concerns about diagnostic speed, accuracy, resource use and variation in practice are amplified by concerns about radiation exposure and subsequent iatrogenic cancer risk ${ }^{12}$ and the need for sedation in young and uncooperative patients. $^{3}$

\section{Key messages}

What is already known on this subject

- CDRs can assist emergency staff in determining which children should receive a CT scan after a head injury.

- One of the few CDRs developed for both children and adults is the NEXUS head CT decision tool.

- The NEXUS CDR has not been externally validated in a paediatric-specific cohort.

What this study adds

- We conducted an external validation of the National Emergency X-Radiography Utilisation Study (NEXUS) clinical decision rule (CDR) in a paediatric multicentre setting with a low baseline CT rate.

- NEXUS had high sensitivity in detecting clinically important intracranial injury.

- Half of all unimaged head injured children were positive for NEXUS criteria in a setting where clinicians did not miss any clinically important intracranial injury.

Several child-specific head injury CDRs have been developed using large data sets. ${ }^{4-8}$ This necessitates that clinicians use a CDR for paediatric patients and a separate CDR for adult patients. In contrast, the National Emergency X-Radiography Utilisation Study II (NEXUS II) collaboration aimed to provide a low-risk decision instrument for head injured patients of all ages. ${ }^{9} 10$ This CDR, prospectively derived in a multicentre data set of 13728 patients who underwent CT for their blunt head injury includes eight predictor variables (age over 65 years, evidence of skull fracture, scalp haematoma, neurological deficit, abnormal alertness, abnormal behaviour, coagulopathy or persistent vomiting). A 7-criteria NEXUS II instrument, excluding the age predictor variable, was then tested in the paediatric subgroup of 1666 children included in the original derivation data set, showing a very high sensitivity (98.6\%, 95\% CI 94.9\% to 99.8\%) and negative predictive value (NPV) (99.1\%, 95\% CI 96.9\% to $99.9 \%$ ). However, the NEXUS II CDR has not been externally validated in a child-specific cohort of undifferentiated head injuries. 


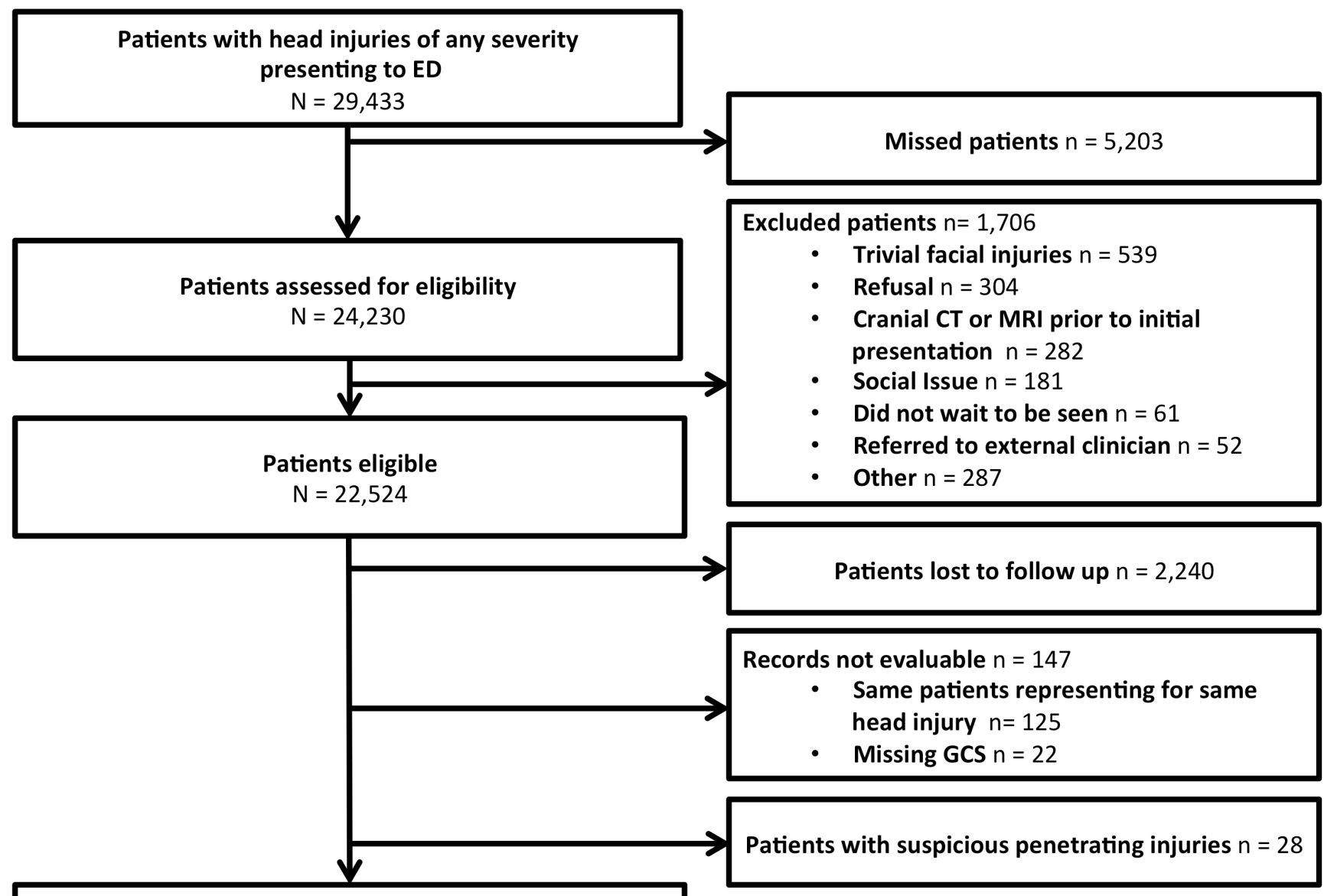

Total number of evaluable patients for analysis

$\mathrm{N}=20,109$

Figure 1 Patients flow. Not including trivial facial injuries defined as a ground level fall or walking or running into an object with no signs or symptoms of injury other than facial abrasions or lacerations below the eyebrows.

Only CDRs that have been derived according to rigorous methodological standards and are externally validated should be implemented in routine clinical practice. ${ }^{4}$ As $>80 \%$ of paediatric emergencies are managed in EDs that care for both adult and paediatric patients CDRs developed to be used for patients of all ages have the potential to be ideal decision instruments for emergency physicians in mixed departments.

We undertook an external validation of the NEXUS II CDR in head injured children using prospectively collected multicentre data outside the derivation setting. ${ }^{11} 12$ We used the NEXUS II predictor variables and the rule-specific outcome of clinically important ICI to determine the diagnostic accuracy of the rule in an undifferentiated cohort of children with head injuries of any severity. We also analysed the accuracy in the cohort that underwent head CT, consistent with the original derivation cohort inclusion criteria.

\section{METHODS}

\section{Study design and setting}

This was a planned secondary analysis of a prospective multicentre observational study, which enrolled children aged $<18$ years presenting with head injury of any severity to 10 paediatric EDs in Australia and New Zealand between April 2011 and November 2014. All EDs are members of the Paediatric
Research in Emergency Departments International Collaborative research network.

While the focus of the parent study ${ }^{11}$ was on the validation of three other paediatric-specific neuroimaging rules ((i) the prediction rule for the identification of children at very low risk of clinically important traumatic brain injury developed by the Paediatric Emergency Care Applied Research Network (PECARN), ${ }^{6}$ (ii) the Canadian Assessment of Tomography for Childhood Head Injury (CATCH) rule ${ }^{7}$ and (iii) the Children's Head Injury Algorithm for the Prediction of Important Clinical Events (CHALICE)) $)^{8}$ published elsewhere, ${ }^{11}$ we also collected the predictor and outcome variables of the NEXUS II rule. ${ }^{9} 10$ Using the published predictor variables and ICI as outcome variable as defined by NEXUS, we assessed the accuracy (sensitivity, specificity, negative predictive value (NPV), and positive predictive value (PPV)) of NEXUS II in patients in the whole cohort of patients, using systematic telephone follow-up data as a surrogate for negative primary outcome of no ICI if no CT scan had been performed. In a secondary analysis, we assessed the accuracy of NEXUS II only in the cohort who underwent a CT scan, similar to the original derivation papers. ${ }^{9}{ }^{10}$ As predictor and outcome variables were not collected verbatim as published, ${ }^{9} 10$ we adapted them based on available data (see online supplementary tables 1 and 2). We also assessed clinician accuracy for 
Table 1 Demographics of the evaluable patients

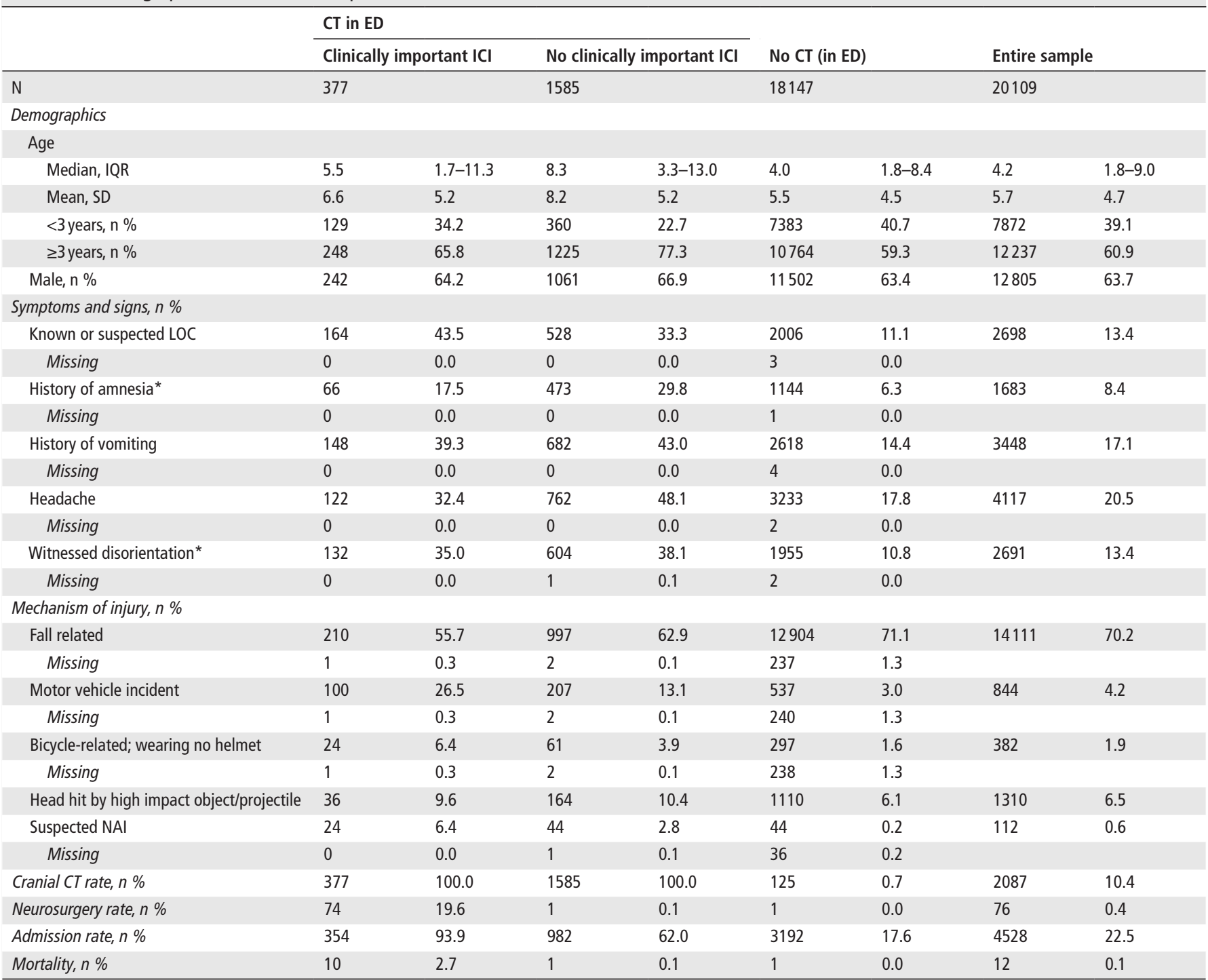

*Preverbal cases excluded.

CT, computed tomography; ED, emergency department; ICI, intracranial injury; LOC, loss of consciousness; NAI, non-accidental injury.

predicting the outcome of ICI by whether they conducted a CT in the ED and compared the results with the accuracy of NEXUS II.

We obtained informed verbal consent from parents/guardians apart from instances of significant life-threatening or fatal injuries where participating ethics committees granted a waiver of consent.

The trial protocol was published in detail elsewhere. ${ }^{12}$ The study was registered with the Australian New Zealand Clinical Trials Registry ACTRN12614000463673 and followed the Standards for Reporting Diagnostic accuracy studies guidelines. ${ }^{13}$

\section{Selection of participants}

Patients were enrolled by the treating ED clinician who collected demographic, epidemiological and clinical data on a standardised case report form prior to any neuroimaging. ED clinicians decided to obtain head CTs at the initial presentation in ED based on their clinical judgement and their own criteria, the study exerted no influence on this process. A research assistant (RA) recorded ED and hospital management data after the visit and conducted a telephone follow-up for patients who had not undergone neuroimaging. Up to six follow-up call attempts were made up to 90 days after injury. In addition, data of any patients who had representations to the study hospitals leading to a CT scan within the follow-up period prior to the phone call were used to assess outcomes. Any patients who had representations to other hospitals based on the telephone follow-up had neuroimaging and neurosurgery reports requested where applicable.

Patients were excluded if they had trivial facial injuries, refused participation, had neuroimaging prior to arrival in ED, did not wait to be seen or were referred for care outside the ED and if there were social issues preventing an approach of the patient or family.

RAs were not blinded to the purpose of the study. Site investigators, RAs and participating ED clinicians received formal training prior to and during the study.

\section{Methods and measurements}

The NEXUS II decision instrument ${ }^{9}{ }^{10}$ was used for this study. It includes eight risk criteria: evidence of significant skull fracture, altered level of alertness, neurological deficit, persistent vomiting, presence of scalp haematoma, abnormal behaviour 
Table 2 Types of injuries and neurosurgical interventions in patients with ICl identified on ED CT $(n=377)$

\begin{tabular}{|c|c|c|}
\hline \multirow[b]{2}{*}{ Type of injury } & \multicolumn{2}{|c|}{ Patients with ICI } \\
\hline & $\mathrm{n}$ & $\%$ \\
\hline \multicolumn{3}{|l|}{ Skull fracture } \\
\hline Depressed & 87 & 23.1 \\
\hline Non-depressed & 152 & 40.3 \\
\hline Basal skull & 35 & 9.3 \\
\hline Diastasis of skull & 34 & 9.0 \\
\hline \multicolumn{3}{|l|}{ Extra-axial bleed } \\
\hline Subdural/extradural haemorrhage & 203 & 53.8 \\
\hline Subarachnoid haemorrhage & 65 & 17.2 \\
\hline \multicolumn{3}{|l|}{ Parenchymal lesions } \\
\hline Parenchyma haemorrhage/contusion & 102 & 27.1 \\
\hline Cerebral oedema & 71 & 18.8 \\
\hline Diffuse axonal injury & 26 & 6.9 \\
\hline Midline shift or brain herniation & 38 & 10.1 \\
\hline Pneumocephalus & 57 & 15.1 \\
\hline $\begin{array}{l}\text { Other (shearing injury, traumatic infarction, sigmoid } \\
\text { sinus thrombosis) }\end{array}$ & 12 & 3.2 \\
\hline \multicolumn{3}{|l|}{ Neurosurgical intervention } \\
\hline Monitoring of intracranial pressure & 44 & 59.5 \\
\hline Elevation of depressed skull fracture & 14 & 18.9 \\
\hline Ventriculostomy & 0 & 0.0 \\
\hline Craniotomy & 43 & 58.1 \\
\hline Haematoma evacuation & 32 & 43.2 \\
\hline Lobectomy & 1 & 1.4 \\
\hline Tissue debridement & 2 & 2.7 \\
\hline Dura repair & 9 & 12.2 \\
\hline
\end{tabular}

$\mathrm{ICl}$, intracranial injury; $\mathrm{CT}$, computed tomography; $\mathrm{ED}$, emergency department.

and coagulopathy and age $>65$ years. Patients fulfilling one or more of these criteria are considered at high risk for ICI and are recommended to undergo a head CT. Similar to Oman et al, ${ }^{10}$ we removed the age criterion as not relevant; online supplementary table 1 presents the definition of the seven risk criteria used ${ }^{10}$ and how closely they matched the predictor variables available from PEACRN, CATCH and CHALICE.

\section{Outcomes}

The definition of ICI applied in this study was based on the original definition proposed by Mower et al, ${ }^{9}$ according to the presence of one or more of a number of CT findings shown in online supplementary table 2 . These were derived from previous clinical work, ${ }^{14}$ which showed that patients with these CT findings may require neurosurgical intervention (craniotomy, intracranial pressure monitoring or mechanical ventilation), or are likely to suffer significant long-term neurological impairment. ${ }^{10} 14$

In this study, we used senior radiologist reports to determine the results of CT scans. RAs and site investigators abstracted these data from CT reports for agreement with the outcome measures and consulted local site radiologists if there was uncertainty in the interpretation of individual scans. De-identified copies of CT findings were provided to the central site. If there was a question as to the classification of the CT, a central site investigator would review the reports and if needed use a third site investigator to resolve disagreements.
A comparison between the NEXUS II CT criteria and the corresponding information used in our study is provided in online supplementary table 2 .

For the descriptive analyses of neurosurgical interventions, we used operative reports. RAs and site investigators abstracted the information from operative reports. If there was a question as to the classification of the operative reports, a central site investigator would review the reports and if needed use a third site investigator to resolve disagreements.

\section{Analysis}

Data were entered into Epidata (The Epidata Association, Odense, Denmark), and later REDCap, ${ }^{15}$ and analysed using Stata 13 (StataCorp, College Station, Texas, USA). Descriptive statistics were calculated for key variables with 95\% CIs where relevant.

Primary analysis was the diagnostic accuracy (sensitivity, specificity, NPV and PPV) of NEXUS II for ICI in patients in the cohort of all presenting patients. In this analysis, patients who did not undergo a CT scan, but were followed up by telephone up to 90 days after the injury were coded as not having ICI. In a secondary analysis, the diagnostic accuracy (sensitivity, specificity, NPV and PPV) of NEXUS II for ICI was tested in the cohort who underwent a CT scan. Finally, we assessed the diagnostic accuracy of clinician practice to detect ICI if a CT scan had been conducted.

Missing predictor variables were treated as missing presumed negative. A sample size calculation had been conducted for the parent study ${ }^{11}{ }^{12}$; no additional sample size calculation was conducted for this substudy and all available patients who fulfilled inclusion criteria were used.

We conducted a secondary analysis where patients with missing predictor variables were excluded.

As in the study by Oman et al, ${ }^{10}$ we also performed a subgroup analysis in children aged $\leq 3$ years. This subgroup analysis was performed in consideration of the fact that assessment of criteria pertaining to behavioural and neurological functioning domains, as well as to other domains, may be more challenging in children of this very young age ${ }^{10}$ and thus may affect the diagnostic accuracy of the CDR instrument.

\section{RESULTS}

\section{Characteristics of study subjects}

A total of 29433 patients presented to the ED with injury of any severity, of which 5203 were missed. Of the remaining 24230 patients assessed for eligibility, 1706 were excluded. Of the 22524 eligible patients, 2240 were lost to follow-up, 147 had records that were not evaluable and 28 were suspected by the ED clinician to have sustained a penetrating head injury; this led to a total number of 20109 patients evaluable for analyses. Patient flow is described in figure 1.

Of $1962(9.6 \%)$ patients who received a CT scan in the ED, $377 / 1962$ (19.2\%) had ICI as defined by NEXUS II (table 1). Mean age of patients was 6.6 (SD 5.2) years for patients with ICI and 8.8 (SD 5.2) years for those without ICI on CT. Overall, $26.3 \%$ of patients with a CT scan were $<3$ years of age. Main signs and symptoms were loss of consciousness and vomiting, main mechanism of injury was fall related. Ten children died from their head injuries. The most frequent types of ICI identified on CT were skull fractures, and subdural/extradural haemorrhages and contusions, with the most frequent neurosurgical interventions $(74,19.6 \%)$ being monitoring of intracranial pressure and craniotomy (table 2). 
Table 3 Frequency and count of individual risk criteria for all children, aged $<3$ years and 3 to $<18$ years

\begin{tabular}{|c|c|c|c|c|c|c|c|c|c|c|c|c|}
\hline \multirow[b]{3}{*}{ Criterion } & \multicolumn{4}{|c|}{$<3$ years } & \multicolumn{4}{|c|}{3 to $<18$ years } & \multicolumn{4}{|l|}{ Total } \\
\hline & \multicolumn{2}{|c|}{ No ICl } & \multicolumn{2}{|l|}{ ICI } & \multicolumn{2}{|c|}{ No ICI } & \multicolumn{2}{|l|}{ ICI } & \multicolumn{2}{|l|}{ No ICI } & \multicolumn{2}{|l|}{ ICI } \\
\hline & $\mathrm{n}$ & $\%$ & $n$ & $\%$ & $\mathrm{n}$ & $\%$ & $\mathrm{n}$ & $\%$ & $\mathrm{n}$ & $\%$ & $\mathrm{n}$ & $\%$ \\
\hline $\mathrm{N}$ & 7743 & & 129 & & 11989 & & 248 & & 19732 & & 377 & \\
\hline \multicolumn{13}{|l|}{ Risk criteria count } \\
\hline 0 & 3503 & 45.2 & 0 & 0.0 & 5817 & 48.5 & 4 & 1.6 & 9320 & 47.2 & 4 & 1.1 \\
\hline 1 & 2899 & 37.4 & 9 & 7.0 & 4003 & 33.4 & 44 & 17.7 & 6902 & 35.0 & 53 & 14.1 \\
\hline 2 & 969 & 12.5 & 40 & 31.0 & 1466 & 12.2 & 59 & 23.8 & 2435 & 12.3 & 99 & 26.3 \\
\hline 3 & 283 & 3.7 & 44 & 34.1 & 500 & 4.2 & 73 & 29.4 & 783 & 4.0 & 117 & 31.0 \\
\hline 4 & 73 & 0.9 & 25 & 19.4 & 167 & 1.4 & 49 & 19.8 & 240 & 1.2 & 74 & 19.6 \\
\hline 5 & 15 & 0.2 & 9 & 7.0 & 34 & 0.3 & 17 & 6.9 & 49 & 0.2 & 26 & 6.9 \\
\hline 6 & 1 & 0.0 & 2 & 1.6 & 2 & 0.0 & 2 & 0.8 & 3 & 0.0 & 4 & 1.1 \\
\hline 7 & 0 & 0.0 & 0 & 0.0 & 0 & 0.0 & 0 & 0.0 & 0 & 0.0 & 0 & 0.0 \\
\hline \multicolumn{13}{|l|}{ Risk criteria } \\
\hline 1. Evidence of skull fracture & 394 & 5.1 & 93 & 72.1 & 1425 & 11.9 & 121 & 48.8 & 1819 & 9.2 & 214 & 56.8 \\
\hline Missing & 95 & 1.2 & 0 & 0.0 & 144 & 1.2 & 1 & 0.4 & 239 & 1.2 & 1 & 0.3 \\
\hline 2. Scalp haematoma & 2796 & 36.1 & 91 & 70.5 & 3272 & 27.3 & 126 & 50.8 & 6068 & 30.8 & 217 & 57.6 \\
\hline Missing & 1 & 0.0 & 0 & 0.0 & 2 & 0.0 & 0 & 0.0 & 3 & 0.0 & 0 & 0.0 \\
\hline 3. Neurological deficits & 181 & 2.3 & 16 & 12.4 & 404 & 3.4 & 25 & 10.1 & 585 & 3.0 & 41 & 10.9 \\
\hline Missing & 2 & 0.0 & 0 & 0.0 & 2 & 0.0 & 0 & 0.0 & 4 & 0.0 & 0 & 0.0 \\
\hline 4. Altered levels of alertness & 604 & 7.8 & 66 & 51.2 & 1059 & 8.8 & 169 & 68.2 & 1663 & 8.4 & 235 & 62.3 \\
\hline Missing & 1 & 0.0 & 0 & 0.0 & 0 & 0.0 & 0 & 0.0 & 1 & 0.0 & 0 & 0.0 \\
\hline 5. Abnormal behaviour & 1372 & 17.7 & 75 & 58.1 & 2010 & 16.8 & 141 & 56.9 & 3382 & 17.1 & 216 & 57.3 \\
\hline Missing & 1 & 0.0 & 0 & 0.0 & 1 & 0.0 & 0 & 0.0 & 2 & 0.0 & 0 & 0.0 \\
\hline 6. Persistent vomiting & 756 & 9.8 & 22 & 17.1 & 1263 & 10.5 & 76 & 30.7 & 2019 & 10.2 & 98 & 26.0 \\
\hline Missing & 3 & 0.0 & 0 & 0.0 & 1 & 0.0 & 0 & 0.0 & 4 & 0.0 & 0 & 0.0 \\
\hline 7. Coagulopathy & 111 & 1.4 & 2 & 1.6 & 195 & 1.6 & 9 & 3.6 & 306 & 1.6 & 11 & 2.9 \\
\hline Missing & 0 & 0.0 & 0 & 0.0 & 1 & 0.0 & 0 & 0.0 & 1 & 0.0 & 0 & 0.0 \\
\hline
\end{tabular}

$\mathrm{ICI}$, intracranial injury.

\section{Main results}

The most frequent positive NEXUS II risk criteria in children with ICI (table 3 ) were scalp haematomas $(217 / 377 ; 57.6 \%)$ and altered level of alertness $(235 / 377 ; 62.3 \%)$. Four patients with CT confirmed ICI had no NEXUS II risk criteria. These four children were aged between 4 and 15 years, presented with a GCS of 15 and fell from height, fell off scooter or were struck by another person at school. All were admitted and none required neurosurgery (see online supplementary table 3). Most children with ICI had two or three positive risk criteria (table 3). When analysing risk criteria among 18022 children who had no initial or subsequent CT scan, 8909 (49.4\%) had at least one risk criterion and $2476(13.7 \%)$ had at least two risk criteria (see online supplementary table 4).

When analysing the diagnostic accuracy of the rule based on all presenting patients, with the assumption that patients not undergoing a CT scan were negative for ICI based on telephone follow-up, it showed a sensitivity of $379 / 383$ (99.0\% (95\% CI $97.3 \%$ to $99.7 \%)$ ) and specificity of $9320 / 19726(47.2 \%(95 \%$ CI $46.5 \%$ to $47.9 \%$ )) (table 4 ). When assessing the accuracy of NEXUS II based on initial CT scan in ED, the sensitivity for ICI based on the NEXUS II CDR was 373/377 (98.9\%; 95\% CI $97.3 \%$ to $99.7 \%$ ) and specificity $156 / 1585$ (9.8\%; $95 \%$ CI $8.4 \%$ to $11.4 \%$ ) (table 4 ). Results were similar when all CTs performed at any time point were included and in children aged $<3$ and $\geq 3$ years (table 5 ). The sensitivity of NEXUS II increased with the number of risk criteria (table 6). We also conducted a sensitivity analysis where patients who had a CT scan with missing risk criteria were excluded. Accuracy results were unchanged (see online supplementary table 5). Clinician accuracy in detecting ICI without the rule was 377/377 (100.0 (95\% CI 99.0\% to $100.0 \%)$ ) and specificity was $18147 / 19732$ (92.0\% (95\% CI 91.6\% to 92.3\%)) (table 4).

\section{DISCUSSION}

In this multicentre validation study, we found NEXUS II to have high sensitivity in detecting the NEXUS-specific outcome of ICI in the overall cohort and in the cohort who underwent CT scanning. Four patients were missed by the rule, that is, had no NEXUS II risk criteria but were positive for ICI; none of them required neurosurgery. Overall accuracy results did not change when patients were excluded who had missing information for NEXUS criteria. Both high sensitivity (98.9\%; 95\% CI 97.3\% to $99.7 \%)$ and low specificity $(9.8 \%$; $95 \%$ CI $8.4 \%$ to $11.4 \%)$ in the CT-only cohort were similar to the analysis of the original NEXUS data overall ${ }^{9}$ and for the paediatric cohort in particular (sensitivity $98.6 \%$ (95\% CI 94.9 to 99.8 ); specificity $15.1 \%$ (95\% CI 13.3 to 16.9$)) .{ }^{10}$ Our data set differed from the NEXUS II cohort in that more young children were enrolled compared with the 'J'-shaped distribution with an increased number of teenagers in NEXUS.

External validation for NEXUS II in children is limited. In three paediatric studies from Finland, ${ }^{16}$ Italy $^{17}$ and the USA ${ }^{18}$ outside the derivation setting, NEXUS II was assessed in terms of accuracy and compared with other head injury rules. All were limited by being conducted in single-centre settings and by the retrospective nature of data extraction ${ }^{16} 18$ or the use of 
Table 4 Accuracy of NEXUS II to detect clinically significant ICI, tested by presence of any risk criteria (of the seven) and clinician accuracy to detect ICI without NEXUS ( $n=20109$ )

\begin{tabular}{|c|c|c|}
\hline & \multicolumn{2}{|l|}{ Risk criteria } \\
\hline & Positive & Negative \\
\hline \multicolumn{3}{|c|}{ Accuracy NEXUS II Total Cohort ( $\mathrm{n}=20$ 109) } \\
\hline Positive ICI & 379 & 4 \\
\hline Negative ICI & 10406 & 9320 \\
\hline Sensitivity $(95 \% \mathrm{Cl})$ & $379 / 383$ & 99.0 (97.3 to 99.7$)$ \\
\hline Specificity $(95 \% \mathrm{Cl})$ & $9320 / 19726$ & 47.2 (46.5 to 47.9$)$ \\
\hline PPV $(95 \% \mathrm{Cl})$ & $379 / 10785$ & 3.5 (3.2 to 3.9$)$ \\
\hline NPV $(95 \% \mathrm{Cl})$ & $9320 / 9324$ & $100.0(99.9$ to 100.0$)$ \\
\hline \multicolumn{3}{|c|}{ Accuracy NEXUS II initial CT scan in ED ( $\mathrm{n}=1962)$} \\
\hline Positive ICI & 373 & 4 \\
\hline Negative ICl & 1429 & 156 \\
\hline Sensitivity $(95 \% \mathrm{Cl})$ & $373 / 377$ & 98.9 (97.3 to 99.7$)$ \\
\hline Specificity $(95 \% \mathrm{Cl})$ & $156 / 1585$ & $9.8(8.4$ to 11.4$)$ \\
\hline PPV $(95 \% \mathrm{Cl})$ & $373 / 1802$ & 20.7 (18.8 to 22.6$)$ \\
\hline NPV $(95 \% \mathrm{Cl})$ & 156/160 & 97.5 (93.7 to 99.3$)$ \\
\hline \multicolumn{3}{|c|}{ Accuracy NEXUS II CT at any time ( $n=2087)$} \\
\hline Positive ICl & 379 & 4 \\
\hline Negative ICI & 1497 & 207 \\
\hline Sensitivity $(95 \% \mathrm{Cl})$ & $379 / 383$ & 99.0 (97.3 to 99.7$)$ \\
\hline Specificity $(95 \% \mathrm{Cl})$ & $207 / 1704$ & 12.1 (10.6 to 13.8$)$ \\
\hline $\operatorname{PPV}(95 \% \mathrm{Cl})$ & $379 / 1876$ & 20.2 (18.4 to 22.1$)$ \\
\hline \multirow[t]{3}{*}{ NPV $(95 \% \mathrm{Cl})$} & 207/211 & 98.1 (95.2 to 99.5$)$ \\
\hline & \multicolumn{2}{|l|}{ Initial CT } \\
\hline & Yes & No \\
\hline \multicolumn{3}{|c|}{ Clinician accuracy of initial CT scan in ED ( $n=20109)$} \\
\hline Positive ICI & 377 & 0 \\
\hline Negative ICI & 1585 & 18147 \\
\hline Sensitivity $(95 \% \mathrm{Cl})$ & $377 / 377$ & $100.0(99.0$ to 100.0$)$ \\
\hline Specificity $(95 \% \mathrm{Cl})$ & $18147 / 19732$ & $92.0(91.6$ to 92.3$)$ \\
\hline $\operatorname{PPV}(95 \% \mathrm{Cl})$ & $377 / 1962$ & $19.2(17.5$ to 21.0$)$ \\
\hline NPV $(95 \% \mathrm{Cl})$ & $18147 / 18147$ & $100.0(100.0$ to 100.0$)$ \\
\hline
\end{tabular}

ICI, intracranial injury; NEXUS, National Emergency X-Radiography Utilisation Study; NPV, negative predictive value; PPV, positive predictive value.

a prospective data set collected before the NEXUS II derivation data had been published. ${ }^{17}$ Neither paper lists in detail how the NEXUS definitions were modified to conform with pre-existing data sets. NEXUS sensitivities were reported at 96\% (95\% CI 90 to 99$),{ }^{16} 88.9 \%$ (95\% CI 63.9 to 95.6$)^{17}$ and $78.3 \%(95 \%$ CI 69.9 to 86.7$),{ }^{18}$ respectively. It is not clear if a multicentre prospective study of NEXUS II from Korea includes any children. ${ }^{19}$ Recently, the original team which derived the NEXUS II CDR conducted a validation study in a new data set including 11750 blunt head injuries ${ }^{20}$; in an analysis of the paediatric cohort of 1018 children sensitivity was $98.0 \%$ (95\% CI $89.1 \%$ to $99.9 \%$ ) and specificity of $34.0 \%$ (95\% CI $31.0 \%$ to $37.0 \%)$ for the assessment of high-risk status in patients with ICI. ${ }^{21}$ However, similar to the derivation cohort only patient who had received a CT scan were included in the study.

While we also followed the original adult and paediatric papers for NEXUS II $^{9}{ }^{10}$ by analysing rule accuracy (external validation) solely based on patients who actually underwent CT scanning, in particular as CT imaging was required for outcome assessment, this does not reflect how rules such as NEXUS II may actually be used in the clinical setting. Therefore, we primarily analysed the accuracy using all patients, including those without CT scans; while sensitivity was similar, specificity was higher in the overall cohort compared with the CT-only cohort. Of 18022 head injured children in our study who did not undergo CT imaging, 49.4\% of these patients fulfilled at least one of the NEXUS predictor variables and therefore, based on the rule, were deemed not at very low risk. If this rule was applied and followed in an undifferentiated cohort of paediatric patients, it would have the potential to increase the head CT rate. When adding predictor positive patients who underwent any CT scan $(\mathrm{n}=1497)$ and those who did not $(\mathrm{n}=8909), 51.7 \%(10406$ of 20 109) of all head injured children would be required to undergo CT imaging as compared with 10.4\% (2087 of 20 109) who actually did, an increase of about $400 \%$. This is particularly striking considering the high sensitivity-where clinicians did not miss a single patient with ICI-and specificity of clinician practice at the participating sites without using the NEXUS rule.

NEXUS II used ICI as primary outcome. Although the outcome was consensus based and aimed to capture CT changes that may require neurosurgical intervention, 'or lead to rapid deterioration or significant long-term neurological impairment', the actual criteria used to define ICI were solely based on recorded CT changes. ${ }^{9} 22$ Other paediatric CDRs, such as PECARN, use definitions of clinically important traumatic brain injury that explicitly require, in addition to specified CT changes, relevant clinical changes, such as admission $>2$ days or intubation $>1$ day (in addition to death or neurosurgery). ${ }^{6}$ Such tightening of the outcome definition would likely change sensitivity and specificity calculations of NEXUS II in both the derivation data set and in our data.

This study has a number of limitations. The predictor and outcome variables for the NEXUS II CDR would have ideally been collected verbatim. Any changes in definitions and wording

Table 5 Accuracy of NEXUS II to detect clinically significant ICI, tested by presence of any risk criteria (of the seven) in children aged $<3$ and 3 to $<18$ years

\begin{tabular}{|c|c|c|c|c|c|}
\hline \multicolumn{3}{|l|}{ Total cohort, $<3$ years } & \multicolumn{3}{|c|}{ Total cohort, 3 to $<18$ years } \\
\hline & \multicolumn{2}{|c|}{ Risk criteria } & & \multicolumn{2}{|l|}{ Risk criteria } \\
\hline & Positive & Negative & & Positive & Negative \\
\hline Positive ICI & 130 & 0 & Positive ICI & 249 & 4 \\
\hline Negative ICI & 4239 & 3503 & Negative ICl & 6167 & 5817 \\
\hline Sensitivity $(95 \% \mathrm{Cl})$ & $130 / 130$ & $100.0(97.2$ to 100.0$)$ & Sensitivity $(95 \% \mathrm{Cl})$ & $249 / 253$ & 98.4 (96.0 to 99.6$)$ \\
\hline Specificity $(95 \% \mathrm{Cl})$ & $3503 / 7742$ & $45.2(44.1$ to 46.4$)$ & Specificity $(95 \% \mathrm{Cl})$ & $5817 / 11984$ & 48.5 (47.6 to 49.4$)$ \\
\hline PPV $(95 \% \mathrm{Cl})$ & $130 / 4369$ & 3.0 (2.5 to 3.5$)$ & PPV $(95 \% \mathrm{Cl})$ & $249 / 6416$ & 3.9 (3.4 to 4.4$)$ \\
\hline NPV $(95 \% \mathrm{Cl})$ & $3503 / 3503$ & $100.0(99.9$ to 100.0$)$ & NPV $(95 \% \mathrm{Cl})$ & $5817 / 5821$ & $99.9(99.8$ to 100.0$)$ \\
\hline
\end{tabular}

$\mathrm{ICl}$, intracranial injury; NPV, negative predictive value; PPV, positive predictive value. 
Table 6 Sensitivity, specificity, positive predictive value (PPV) and negative predictive value (NPV) of risk criteria count (cumulative) and independent risk criteria in total patient cohort $(n=20109)$

\begin{tabular}{|c|c|c|c|c|c|c|c|c|}
\hline & Sensitivity & $(95 \% \mathrm{Cl})$ & Specificity & $(95 \% \mathrm{Cl})$ & PPV & $(95 \% \mathrm{Cl})$ & NPV & $(95 \% \mathrm{Cl})$ \\
\hline \multicolumn{9}{|l|}{ Risk criteria count } \\
\hline 0 & - & & - & & - & & - & \\
\hline 1 & 3.5 & (3.2 to to 3.9 ) & 100.0 & (99.9 to 100.0 ) & 99.0 & (97.3 to 99.7 ) & 47.2 & (46.5 to 47.9 ) \\
\hline 2 & 8.4 & (7.6 to 9.4 ) & 99.6 & (99.5 to 99.7 ) & 84.3 & (80.3 to 87.8 ) & 82.2 & (81.7 to 82.8 ) \\
\hline 3 & 17.1 & (15.1 to 19.3$)$ & 99.1 & (99.0 to 99.3 ) & 58.0 & (52.8 to 63.0 ) & 94.6 & (94.2 to 94.9 ) \\
\hline 4 & 26.3 & (22.0 to 30.9 ) & 98.6 & (98.4 to 98.7 ) & 27.2 & (22.8 to 31.9 ) & 98.5 & (98.3 to 98.7 ) \\
\hline 5 & 36.6 & (26.2 to 48.0 ) & 98.2 & (98.0 to 98.4 ) & 7.8 & (5.3 to 11.0 ) & 99.7 & (99.7 to 99.8 ) \\
\hline 6 & 57.1 & (18.4 to 90.1 ) & 98.1 & (97.9 to 98.3 ) & 1.0 & (0.3 to 2.7 ) & 100.0 & (100.0 to 100.0$)$ \\
\hline 7 & - & & - & & - & & - & \\
\hline \multicolumn{9}{|l|}{ Risk criteria } \\
\hline $\begin{array}{l}\text { 1. Evidence of } \\
\text { skull fracture }\end{array}$ & 10.6 & (9.3 to 12.0 ) & 99.1 & (98.9 to 99.2 ) & 56.4 & (51.3 to 61.4 ) & 90.8 & (90.4 to 91.2 ) \\
\hline $\begin{array}{l}\text { 2. Scalp } \\
\text { haematoma }\end{array}$ & 4.1 & (3.6 to 4.7 ) & 99.0 & (98.8 to 99.2 ) & 62.4 & (57.3 to 67.3 ) & 71.8 & (71.1 to 72.4 ) \\
\hline $\begin{array}{l}\text { 3. Neurological } \\
\text { deficits }\end{array}$ & 6.5 & (4.7 to 8.8 ) & 98.2 & (98.1 to 98.4 ) & 10.7 & (7.8 to 14.2 ) & 97.0 & (96.8 to 97.3 ) \\
\hline $\begin{array}{l}\text { 4. Altered levels } \\
\text { of alertness }\end{array}$ & 12.4 & (10.9 to 13.9 ) & 99.2 & (99.0 to 99.3 ) & 61.4 & (56.3 to 66.3 ) & 91.6 & (91.2 to 92.0 ) \\
\hline $\begin{array}{l}\text { 5. Abnormal } \\
\text { behaviour }\end{array}$ & 6.1 & (5.3 to 6.9 ) & 99.0 & (98.8 to 99.1 ) & 56.9 & (51.8 to 61.9 ) & 82.9 & (82.3 to 83.4 ) \\
\hline $\begin{array}{l}\text { 6. Persistent } \\
\text { vomiting }\end{array}$ & 4.8 & (3.9 to 5.8 ) & 98.4 & (98.2 to 98.6 ) & 26.4 & (22.0 to 31.1 ) & 89.8 & (89.3 to 90.2 ) \\
\hline 7. Coagulopathy & 3.8 & (2.0 to 6.5 ) & 98.1 & (97.9 to 98.3 ) & 3.1 & (1.6 to 5.4 ) & 98.5 & (98.3 to 98.6 ) \\
\hline
\end{tabular}

of head injury rules have the potential to alter the final results. ${ }^{23}$ The focus of the parent study ${ }^{11}$ used for this paper, however, was on the paediatric-specific CATCH, CHALICE and PECARN rules. $^{6-8}$ We felt that by collecting the predictor and outcome variables of three rules in detail, the modified definitions could be closely approximated to the actual NEXUS II criteria used for this study. A further limitation of this study was a $10 \%$ loss to follow-up in the parent study, which may have affected the analysis including patients who did not undergo CT scanning. In the NEXUS derivation study as well as in the validations study by the same group, patients who were not imaged were generally not followed up. ${ }^{9}$ In our study, participating sites were usually also the only paediatric neurosurgical centres in the local areas. A further limitation is that CT scans were not reviewed centrally; rather CT reports were used to assess ICI. Finally, this study reflects practice at tertiary Australian and New Zealand centres, where imaging rates are generally lower than in North America ${ }^{671124}$ and no specific rule predominates. ${ }^{25}$ The developers of NEXUS presumed that patients in the derivation study perceived by clinicians to be at high risk (independent of the NEXUS criteria per se) would be imaged by treating clinicians anyway. Therefore, no comprehensive follow-up system was put in place and only a small fraction of the original derivation cohort $(9.2 \%)$ were followed up by interview ${ }^{9}$; it is unclear how many head injured children were included in this cohort. Although no denominator of patients presenting to participating EDs or the actual imaging rate at NEXUS sites was provided in the NEXUS derivation or validation papers, ${ }^{9} 102021$ in settings with a presumably high CT rate this may accurately capture all or most relevant patients. In settings with a much lower scan rate, such as in our setting, this may not be true and patients may be missed unless a comprehensive follow-up system is in place.

In this multicentre prospective external validation study, the NEXUS II CDR had high sensitivity and low specificity similar to the derivation study. However, as approximately half of patients who did not receive a CT scan were positive for NEXUS II risk criteria, this CDR has the potential to lead to increased scanning rates in a setting with high clinician accuracy.

\section{Author affiliations}

${ }^{1}$ Emergency Department, Royal Children's Hospital, Melbourne, Victoria, Australia ${ }^{2}$ Murdoch Children's Research Institute, Parkville, Victoria, Australia

${ }^{3}$ Department of Paediatrics, Faculty of Medicine, Dentistry and Health Sciences, University of Melbourne, Melbourne, Victoria, Australia

${ }^{4}$ Emergency Department, Starship Children's Health, Auckland, New Zealand ${ }^{5}$ Liggins Institute, University of Auckland, Auckland, New Zealand

${ }^{6}$ Emergency Department, Princess Margaret Hospital for Children, Perth, Western Australia, Australia

${ }^{7}$ Schools of Medicine, University of Western Australia, Crawley, Western Australia, Australia

${ }^{8}$ Emergency Department, Lady Cilento Children's Hospital, Brisbane and Child Health Research Centre, School of Medicine, The University of Queensland, South Brisbane, Queensland, Australia

${ }^{9}$ Emergency Department, Women's and Children's Hospital Adelaide, North Adelaide, South Australia, Australia

${ }^{10}$ Emergency Department, The Children's Hospital at Westmead, Sydney, New South Wales, Australia

${ }^{11 E m e r g e n c y ~ D e p a r t m e n t, ~ M o n a s h ~ C h i l d r e n ' s ~ H o s p i t a l, ~ P a r k v i l l e, ~ V i c t o r i a, ~ A u s t r a l i a ~}$ ${ }^{12}$ Emergency Department, Townsville Hospital, Townsville, Queensland, Australia

${ }^{13}$ Emergency Department, Kidzfirst Middlemore Hospital, Auckland, New Zealand

${ }^{14}$ Department of Women's and Child's Health, University of Padova, Padova, Italy

${ }^{15}$ Academic Department of Emergency Care, University of the West of England,

Bristol, UK

${ }^{16}$ Emergency Department, Bristol Royal Children's Hospital, Bristol, UK

Acknowledgements The authors would like to thank the participating families, emergency department staff and research staff at participating sites.

Contributors FEB: conceived the study, obtained grant funding, designed the study, provided overall supervision, interpreted the data, wrote the initial draft of the paper, gave final approval to be published and agreed to be accountable for all aspects of the work. MLB, NP, AK, SD, JAC, YG, JF, JN, MDL, MA, SH, SB, LMC, EO, SRD: designed the study, obtained the data, provided supervision, interpreted the data, drafted or revised it critically, gave final approval to be published and agreed to be accountable for all aspects of the work. SD: designed the study, supervised the analysis of the data, contributed to the interpretation of the data, revised the paper critically, gave final approval to be published and agreed to be accountable for all aspects of the work. 
Funding The study was funded by grants from the National Health and Medical Research Council (project grant GNT1046727, Centre of Research Excellence for Paediatric Emergency Medicine GNT1058560), Canberra, Australia; the Murdoch Childrens Research Institute, Melbourne, Australia; the Emergency Medicine Foundation (EMPJ-11162), Brisbane, Australia; Perpetual Philanthropic Services (2012/1140), Australia; Auckland Medical Research Foundation (No. 3112011) and the A + Trust (Auckland District Health Board), Auckland, New Zealand; WA Health Targeted Research Funds 2013, Perth, Australia; the Townsville Hospital and Health Service Private Practice Research and Education Trust Fund, Townsville, Australia and supported by the Victorian Government's Infrastructure Support Program, Melbourne, Australia. FEB's time was part funded by a grant from the Royal Children's Hospital Foundation, Melbourne, Australia, an NHMRC Practitioner Fellowship GNT1124466 and a Melbourne Children's Clinician Scientist Fellowship. SRD's time was part funded by the Health Research Council of New Zealand (HRC13/556).

Competing interests None declared.

Patient consent Not required.

Ethics approval The study was approved by the Royal Children's Hospital, Melbourne, Australia.

Provenance and peer review Not commissioned; externally peer reviewed.

Data sharing statement There are no additional data available.

\section{REFERENCES}

1 Pearce MS, Salotti JA, Little MP, et al. Radiation exposure from CT scans in childhood and subsequent risk of leukaemia and brain tumours: a retrospective cohort study. Lancet 2012;380:499-505.

2 Miglioretti $\mathrm{DL}$, Johnson E, Williams $\mathrm{A}$, et al. The use of computed tomography in pediatrics and the associated radiation exposure and estimated cancer risk. JAMA Pediatr 2013;167:700-7.

3 Goldwasser T, Bressan S, Oakley E, et al. Use of sedation in children receiving computed tomography after head injuries. Eur J Emerg Med 2015;22:413-8.

4 Pickering A, Harnan S, Fitzgerald P, et al. Clinical decision rules for children with minor head injury: a systematic review. Arch Dis Child 2011;96:414-21.

5 Lyttle MD, Crowe L, Oakley E, et al. Comparing CATCH, CHALICE and PECARN clinical decision rules for paediatric head injuries. Emerg Med J 2012;29:785-94.

6 Kuppermann N, Holmes JF, Dayan PS, et al. Identification of children at very low risk of clinically-important brain injuries after head trauma: a prospective cohort study. Lancet 2009:374:1160-70.

7 Osmond MH, Klassen TP, Wells GA, et al. CATCH: a clinical decision rule for the use of computed tomography in children with minor head injury. CMAJ 2010;182:341-8.

8 Dunning J, Daly JP, Lomas JP, et al. Derivation of the children's head injury algorithm for the prediction of important clinical events decision rule for head injury in children. Arch Dis Child 2006;91:885-91.

9 Mower WR, Hoffman JR, Herbert M, et al. Developing a decision instrument to guide computed tomographic imaging of blunt head injury patients. J Trauma 2005:59:954-9.
10 Oman JA, Cooper RJ, Holmes JF, et al. Performance of a decision rule to predict need for computed tomography among children with blunt head trauma. Pediatrics 2006;117:e238-e246.

11 Babl FE, Borland ML, Phillips N, et al. Accuracy of PECARN, CATCH, and CHALICE head injury decision rules in children: a prospective cohort study. Lancet 2017:389:2393-402.

12 Babl FE, Lyttle MD, Bressan S, et al. A prospective observational study to assess the diagnostic accuracy of clinical decision rules for children presenting to emergency departments after head injuries (protocol): the Australasian Paediatric Head Injury Rules Study (APHIRST). BMC Pediatr 2014;14:148.

13 Bossuyt PM, Reitsma JB, Bruns DE, et al. Toward complete and accurate reporting of studies of diagnostic accuracy: the STARD initiative. Acad Radiol 2003;10:664-9.

14 Atzema C, Mower WR, Hoffman JR, et al. Defining "therapeutically inconsequential" head computed tomographic findings in patients with blunt head trauma. Ann Emerg Med 2004:44:47-56.

15 Harris PA, Taylor R, Thielke R, et al. Research electronic data capture (REDCap)--a metadata-driven methodology and workflow process for providing translational research informatics support. J Biomed Inform 2009;42:377-81.

16 Klemetti S, Uhari M, Pokka T, et al. Evaluation of Decision Rules for Identifying Serious Consequences of Traumatic Head Injuries in Pediatric Patients. Pediatr Emerg Care 2009;25:811-5.

17 Fabbri A, Servadei F, Marchesini G, et al. Analysis of different decision aids for clinical use in pediatric head injury in an emergency department of a general hospital. $J$ Trauma 2011;70:E79-E83.

18 Schachar JL, Zampolin RL, Miller TS, et al. External validation of the New Orleans Criteria (NOC), the Canadian CT Head Rule (CCHR) and the National Emergency X-Radiography Utilization Study II (NEXUS II) for CT scanning in pediatric patients with minor head injury in a non-trauma center. Pediatr Radiol 2011:41:971-9.

19 Ro YS, Shin SD, Holmes JF, et al. Comparison of clinical performance of cranial computed tomography rules in patients with minor head injury: a multicenter prospective study. Acad Emerg Med 2011;18:597-604.

20 Mower WR, Gupta M, Rodriguez R, et al. Validation of the sensitivity of the National Emergency X-Radiography Utilization Study (NEXUS) Head computed tomographic (CT) decision instrument for selective imaging of blunt head injury patients: An observational study. PLoS Med 2017;14:e1002313.

21 Gupta M, Mower WR, Rodriguez RM, et al. Validation of the pediatric nexus ii head computed tomography decision instrument for selective imaging of pediatric patients with blunt head trauma. Acad Emerg Med 2018:729-37.

22 Mower WR, Hoffman JR, Herbert M, et al. Developing a clinical decision instrument to rule out intracranial injuries in patients with minor head trauma: methodology of the NEXUS II investigation. Ann Emerg Med 2002;40:505-15.

23 Sun BC, Hoffman JR, Mower WR. Evaluation of a modified prediction instrument to identify significant pediatric intracranial injury after blunt head trauma. Ann Emerg Med 2007;49:325-32.

24 Oakley E, May R, Hoeppner T, et al. Computed tomography for head injuries in children: Change in Australian usage rates over time. Emerg Med Australas 2017;29:192-7.

25 Lockie FD, Dalton S, Oakley E, et al. Triggers for head computed tomography following paediatric head injury: Comparison of physicians' reported practice and clinical decision rules. Emerg Med Australas 2013:25:75-82. 